
\title{
28 Research Suare \\ Potential human rabies exposure in Nunavik: importance of age and dogs
}

Sarah Mediouni ( $\nabla$ sarah.mediouni@umontreal.ca )

Universite de Montreal https://orcid.org/0000-0003-2026-5623

Mario Brisson

Public Health Department of Nunavik

André Ravel

Universite de Montreal

Research article

Keywords: Animal, dog, injury, bite, children, Nunavik, young adult, rabies, management, public health

Posted Date: November 15th, 2019

DOI: https://doi.org/10.21203/rs.2.17363/v1

License: (1) This work is licensed under a Creative Commons Attribution 4.0 International License.

Read Full License

Version of Record: A version of this preprint was published at BMC Public Health on April 29th, 2020. See the published version at https://doi.org/10.1186/s12889-020-08606-8. 


\section{Abstract}

Background In Nunavik, arctic rabies is still endemic with spillover from wildlife to dogs. The prevention of human exposure and the management of potential exposure is a high public health concern there.

Methods The study retrospectively described cases of potential exposure to rabies in human reported to the Nunavik Public Health Board using the registry of declared cases. Multi-correspondence analysis as well as univariable and multivariable regression models were used to appraise the difference between children and adults and the importance of dogs.

Results From 2008 to 2017, 320 cases of potential exposures to rabies were reported, 92\% linked to dogs. The annual incidence rate was 2.5 per 1,000 population. The incidence increased significantly during the study period without clear explanation for that. Fifteen exposures actually were with rabid animals, mostly dogs (9 out of the 15). No human cases of rabies occurred thank to adequate medical case management. Two specific profiles for potential exposure to rabies were identified based on age and gender. Children $(<15 \mathrm{y} / 0)$, male or female, were more likely to be exposed through playing with dogs and more often injured in the head and/or the neck. Young male adult cases (aged 15 to $34 \mathrm{y} / \mathrm{o}$ ) were more involved with wildlife than other age groups and mostly injured in the upper limbs and as a reaction from the animal.

Conclusions Rabies being a serious and genuine public health threat in Nunavik, potential exposure to rabies needs to be prevented and prevention measures should be tailored to the two risk profiles identified based on age, gender and the animal involved.

\section{Introduction}

Dog attacks and bites have been acknowledged as a public health problem for decades (1, 2). Amongst other issues related to these injuries, rabies exposure remains the most threatening consequence and therefore a major concern for health authorities (3-6). In Canada, a study conducted in 22 municipalities across 7 different provinces showed an annual dog bite incidence rate ranging from 0 to 1 per 1,000 population (7). However, reported dog bites represent only a small fraction of the true incidence, between 20 to $50 \%$ (8-10). In fact, studies conducted in the United States (US) showed that annual dog bite incidence ranged from 1 to 18 per 1,000 population when taking into account non declared bites $(11,12)$.

In Québec, Canada, an investigation report of the Ministry of Agriculture, Fisheries and Food (MAPAQ) for 2016 showed an annual incidence of injuries from domestic animal of 2.43 per 1,000 population in northern Quebec compared to a rate of 0.1 to 0.7 per 1,000 population in the southern regions, 60 to $96 \%$ of those injuries were related to dogs (MAPAQ, unpublished observations). The tendency for such disparities have been previously mentioned in other studies throughout Canada, the US and other parts of the world, and associated to inequalities in socioeconomic status (SES) (13-15). Furthermore, in Alaska, there was a significant difference between the average annual rate for dog bites in Native people when compared to non-Alaska Natives (0.1 and 0.03/ 1,000 inhabitants, respectively) (13). 
Most studies have pointed out that dog bites are also an unequal burden when it comes to age as children are most likely to be victims of dog attacks due to their physical attributes as well as their limited cognitive development leading to poor judgment in risky situations $(4,16-18)$. The Canadian Hospital Injury Reporting and Prevention Program (CHIRPP) report shows that dog bites feature among the five most common injury causes in children aged from 5 to $9 \mathrm{y} / \mathrm{o}$ (19). According to the same source, the hospitalization rate was almost three times higher for children aged 1 to $4 \mathrm{y} / \mathrm{o}$ compared to the general population (all ages). Additionally, studies have shown that children tend to suffer the most severe consequences; in fact, a study conducted on children admitted to tertiary emergency departments in Edmonton, Alberta, between 1998 and 2002 for dog bites showed that most victims required sutures (54\%), and $25 \%$ of them had injuries that were classified as severe (20).

Nunavik is situated in the arctic region of Québec, north of the 55th parallel. With a vast land area of $507,000 \mathrm{~km}^{2}$, it covers almost one third of the largest province in Canada while having a very low population density (21). Nunavik is inhabited by indigenous, mainly Inuit, communities located in 14 different villages along the coasts of Hudson Bay and Ungava Bay, only four of these communities have a population of more than 1,000 people (22). In these societies, dogs have played an important role in the life of Inuit, having impact on both their physical and mental health and well-being. By taking part of their daily activities such as hunting, movement and travel, companionship, protection and guard, they have always been recognized as key members of the community (23-25) even though there are many problems that seem to be directly linked to roaming dogs and uncontrolled dog populations (26).

In Nunavik, rabies is a serious public health threat (4). The current endemic situation for arctic fox rabies goes back to 1945, when an epizootic fox rabies originated in arctic Canada (27). Cases of rabid animals have been declared in northern Québec almost every year since then $(27,28)$. And although dogs are not directly reservoir for the disease, they can play an important role as an intermediate for rabies exposure between wildlife and humans, the most common form of exposure is through dog bites (6). Despite the efforts of public health and public safety sectors, the issue remains unresolved (26) and so far, little research has been conducted to explore all facets of the problem and venues for sustainable solutions. Furthermore, even though multiple studies have investigated dog bites epidemiology, few to none have explored the specific and general context surrounding dog bites and their management from a one-health perspective $(16,29,30)$.

The purpose of the present study was to retrospectively describe human cases of potential exposure to rabies in Nunavik, particularly those involving dogs, and to determine the differences between children and adult cases if any. To facilitate the interpretation of potential differences over time, between villages or between children and adult cases, specific contextual information related to the rabies dynamic, to the dog population and health, and to the management and report of potential human exposure to rabies to public health authorities and to animal health authorities were collected and used.

\section{Methods}


This epidemiological study used a mixed design. It retrospectively analyzed an available database of human cases of potential exposure to rabies over 2008-2017. It collected and analyzed contextual information about the management and report of such human cases, about the management of the animals involved (mostly domestic ones and mainly dogs) as well as the dog population dynamics and rabies dynamics in Nunavik over the same period.

\section{Epidemiological analysis}

\section{Data sources}

The tidied database of human cases of exposure to rabies as well as the dictionary of variables were provided by the Nunavik Regional Public Health Board (NRPHB) for the years 1996 to 2017. This database had been previously developed, updated and cleaned (Kalaba, unpublished observations). The information contained is mainly derived from the declaration forms filled out by front line health professionals whenever a person is presented to the health center for an animal related injury (5). The management form and the test reports for rabies provide data on the victim and the animal follow-up, respectively. The dataset was restricted to the study period based on the reporting year. Three potential exposures that had occurred outside Nunavik were removed. Demographics of the Nunavik population over the study period was obtained through Quebec's Statistics Institute and used for incidence rate standardization.

\section{Variables}

Original database contained demographic information about the victims (sex, age in years, village where the exposure occurred), the date of the incident (exposure date), the date of the reporting to health authorities (reporting date). Non-available exposure dates were created using the reporting date instead. The exposure site, the exposure type and the animal involved were also available. Data on post-exposure prophylaxis (PEP) included the recommendation decision (PEP decision). Data on animal management included the animal follow-up (put under observation or analyzed for rabies), if the animal has been killed before the observation period was over (culled before); whenever the animal had been tested for rabies, the test result was also available. Finally, a comment field (Comment) provided free information related to the incident.

Upon importing the dataset sheet from excel, we created additional variables. Using the exposure date, we extracted the year, the month, and the weekday of the exposure. We created four age groups for descriptive analyses $(1: 0-4 ; 2: 5-14 ; 3: 15-34 ; 4: 35+y / 0)$; these were restricted to two (children: $0-14$; adults: $15+y / 0)$ for the multivariate analysis. For cases involving a dog, we used the comment field to appraise the circumstances in which the injury occurred whenever any information provided was useful. We defined three main categories of circumstances after the relevant review of literature about aggressive 
behavior in dogs $(5,29,31-34)$. They were: 1$)$ injuries occurring during play or as a form of communication, 2) injuries occurring as a dog reaction to a perceived threat (protection of food, litter or territory, fear of being harmed or a redirected aggression), and 3) injuries occurring as an intended aggression or predation by the dog. We coded every dog-related case accordingly based on the finding of pre-defined keywords in the comment field. When information on the circumstances was provided but ambiguous, we coded the circumstances as inconclusive. When the comment field did not include information about the circumstances, we coded the circumstances as not applicable-N/App.

Missing values were unequally present for the cited variables and throughout the study period. Missing data were predominant for the following variables: PEP decision, animal follow-up and test result and particularly in 2012 and from 2015 to 2017.

\section{Statistical analysis}

We used descriptive statistics to describe the case variables. Average annual incidence per 1,000 habitants was calculated for each village and adjusted for age and sex based on Nunavik population for 2017 using direct standardization $(35,36)$. Uniformity test (two-sided Kolmonov Smirnov: K-S test) was performed to test whether the exposures occurred uniformly across the months and across the weekdays.

The differences between age groups relatively to the other variables were explored in three steps. It started with bivariate description of age and each other variable, followed by a multivariate description, and ended with a formal statistical test. The multivariate description was performed through a multiple correspondence analysis (MCA) exploring the potential patterns between modalities of the following variables: sex, age group, exposure site, exposure type, PEP decision, animal type, animal follow-up and rabies test result. Univariable and multivariable analysis using binary logistic regression was conducted within two case scenarios (all exposures and exposures through dog only), statistical significance was set at a p-value threshold of 0.05. We performed all statistical analyses on R 3.4.2 software using the Stats and MASS packages for multivariate analysis and multiple correspondence analysis, respectively.

\section{Context analysis}

\section{Data collection}

Information was collected about the specific and global context surrounding case management in northern Québec as well as the changes and major events that might have occurred during the study period and over the 14 villages, using semi-structured interviews. We used a mixed approach for recruitment of participants; purposive sampling followed by identifying key stakeholders that are involved directly or indirectly in the animal and/or the human case management. Further participants were then recruited upon referral by initial interviewees. Human health professionals were asked for details on case 
management in Nunavik while animal health specialists were asked about the animal management and/or arctic rabies dynamic during the study period. Local stakeholders were mainly enquired about the dog population dynamics as well as the current situation regarding dogs in Nunavik (restraining, vaccination and licensing). Individual interviews were conducted one-to-one or via the phone. The semistructured interview guide was composed of four to six open-ended questions depending on the extent of the participant's implication and the affiliated organism in the exposure case management: 1) What are your organization's roles and activities and how do they affect the case management or the animal related injury risk in Nunavik? 2) What changes could have occurred during the study period (2008-2017) in those roles and activities? 3) What changes or major events could have occurred in regards to months or seasons? 4) According to you, is there any differences between the 14 villages in regards to case management? 5) According to you, is there any differences between the age groups in regards to these roles and activities? 6) Does your organization detain documentation or additional data related to your answers?

Data collection started in November 2018 and ended in March 2019. Each interview was recorded upon consent from the participants and notes were taken by the research team, the data was then stored for transcription and analysis.

\section{Data analysis}

After each interview, the record and the notes were used to write a brief summary that was then sent to the participant for validation. The validated information gathered in the summaries were then manually triangulated and analyzed according to the interview questions (overall description of the case management, changes over the study period-years, seasonal patterns or changes over the months, differences between the villages, and differences between the age groups).

Throughout the interviews with the stakeholders, we were able to collect additional information on domestic animal related injuries in Québec for 2015 and 2016 through the MAPAQ and on rabies dynamic in Nunavik during the study period through the Canadian Food Inspection Agency's (CFIA).

\section{Results}

\section{Overall description of human cases of potential exposure to rabies}

In total, 320 human cases of potential exposure to rabies were reported in Nunavik from 2008 to 2017, of which 293 (92\%) involved a dog. Cases associated with wildlife were mainly linked to arctic foxes (68\% of 23 cases). Overall, the victims were more often men (62\% of all cases) than women; the proportion being greater among cases not associated with dogs (87\% men) (Table 1). Children aged 5 to 14 years old accounted for one third of 
all cases (Table 1). The majority of injuries were located in the upper $(40 \%)$ or lower (35\%) limbs.

Table 1. Demographic characteristics of potential human exposures to rabies, Nunavik 20082017

\begin{tabular}{|c|c|c|c|c|c|c|}
\hline \multirow[t]{2}{*}{ Variable } & \multicolumn{2}{|c|}{$\begin{array}{l}\text { All injuries } \\
(n=320)\end{array}$} & \multicolumn{2}{|c|}{$\begin{array}{c}\text { Dogs } \\
\left(n=293^{*}\right)\end{array}$} & \multicolumn{2}{|c|}{$\begin{array}{l}\text { Other than dogs } \\
\qquad\left(\mathrm{n}=23^{*}\right)\end{array}$} \\
\hline & $\mathrm{n}$ & $\%$ & $\mathrm{n}$ & $\%$ & $\mathrm{n}$ & $\%$ \\
\hline \multicolumn{7}{|l|}{ Sex } \\
\hline Male & 198 & 61.9 & 176 & 60.1 & 20 & 87 \\
\hline Female & 120 & 37.5 & 115 & 39.2 & 3 & 13 \\
\hline NA & 2 & 0.6 & 2 & 0.7 & 0 & 0 \\
\hline \multicolumn{7}{|c|}{ Age group } \\
\hline$[0-4]$ & 30 & 9.4 & 30 & 10.2 & 0 & 0 \\
\hline [5-14] & 110 & 34.4 & 102 & 34.5 & 5 & 21.7 \\
\hline [15-34] & 114 & 35.6 & 101 & 34.5 & 12 & 52.2 \\
\hline$[35+]$ & 61 & 19.1 & 55 & 18.8 & 6 & 26.1 \\
\hline NA & 5 & 1.6 & 5 & 1.7 & 0 & 0 \\
\hline
\end{tabular}

* Sum is not 320 because the animal type was unknown in 4 cases

Incidence of potential rabies exposure reported to the public health authority increased remarkably during the study period, with a two-fold increase from $2014(\mathrm{n}=31)$ to $2017(n=72)$ (Figure 1). Overall, the incidence based on the exposure date was not uniformly distributed across months, nor across days of the week (K-S test: $\mathrm{D}=1 / \mathrm{critical}$ value $=0.08)(p$-value $<0.01)$, with May and August encompassing $12 \%$ and $13 \%$ of the cases, respectively, and Friday 18\% (Figure 1).

Figure 1 
The adjusted annual incidence by village over the study period varied between 0.45 and 4.6 cases per 1,000 habitants in Kangiqsualujjuaq and Kuujjuarapik, respectively (Table 2). Visually, these incidences appear higher in the villages of Ungava Bay compared to Hudson Bay (Figure 2).

Table 2. Distribution of potential human exposures to rabies by villages, Nunavik, 2008-2017

\begin{tabular}{|c|c|c|c|c|}
\hline $\begin{array}{l}\text { Village (sorted by decreasing } \\
\text { adjusted annual incidence) }\end{array}$ & $\mathrm{n}$ & $\%$ & $\begin{array}{l}\text { Average annual incidence } \\
\text { (per 1,000 population) }\end{array}$ & $\begin{array}{l}\text { Average adjusted annual } \\
\text { incidence (per 1,000 population) } \\
1\end{array}$ \\
\hline Kuujjuarapik & 31 & 9.7 & 4.69 & 4.74 \\
\hline Kangirsuk & 21 & 6.6 & 3.69 & 3.60 \\
\hline Quaqtaq & 14 & 4.4 & 3.59 & 3.53 \\
\hline Kuujjuaq & 88 & 27.5 & 3.50 & 3.68 \\
\hline Salluit & 47 & 14.7 & 3.28 & 3.19 \\
\hline Inukjuak & 48 & 15.0 & 2.76 & 2.72 \\
\hline Ivujivik & 10 & 3.1 & 2.63 & 2.68 \\
\hline Umiujaq & 10 & 3.1 & 2.19 & 2.08 \\
\hline Kangiqsujuaq & 17 & 5.3 & 2.11 & 2.04 \\
\hline Aupaluk & 4 & 1.2 & 2 & 2.73 \\
\hline Akulivik & 7 & 2.2 & 1.09 & 1.04 \\
\hline Tasiujaq & 3 & 0.9 & 0.95 & 0.88 \\
\hline Puvirnituq & 14 & 4.4 & 0.81 & 0.74 \\
\hline Kangiqsualujjuaq & 5 & 1.6 & 0.45 & 0.45 \\
\hline NA & 1 & 0.3 & - & - \\
\hline Total & 320 & 100 & 2.5 & 2.5 \\
\hline
\end{tabular}

1 Cumulative incidences were standardized for both age and sex using direct standardization 
Figure 2

PEP was recommended for $43 \%$ of the cases for which the information was available. It was more frequently recommended in cases involving wildlife (86\%) compared to dogs (38\%). Median PEP duration was 14 days.

Sixty-two percent of dogs involved were held for observation following the exposure; a minor fraction (1.6\%) of them were killed before the follow-up was over. Observation rate increased over the study period from 25\% (3/12) in 2008 to 83\% (60/72) in 2017.

Fifteen rabid animals (6.7\% of all cases) were identified during the study period, of which 9 (60\%) were dogs. Rabid animal proportion was 4\% among dogs and 43\% among wild animals. The number of rabid animals ranged from 0 to 2 per year except for 2015 and 2017, when the number of rabid animals was 6 and 4, respectively, and they were located in seven different villages with one, Ivujivik, accounting for $33 \%$ of all positive cases (Figure 2).

PEP was recommended for all cases associated with a rabid animal with only one exception; careful examination of the case file revealed that the person was in contact with an animal carcass and took all the necessary precautions to avoid contamination while handling it. Therefore, the assessment at the time concluded there were no risk of exposure to rabies. PEP recommendation was a posteriori not required in $35 \%$ of cases, where the animal involved was tested and found not rabid.

The comment field included information in 152 dog-related cases (51.8\% of all cases). Around $40 \%$ of these cases were coded as a dog reaction to a human threat, $17 \%$ occurred during play and 7\% were coded as a direct aggression by the dog, whereas the information was not useful in 38\%. Most exposures during play involved children up to $15 \mathrm{y} / \mathrm{o}$. For reaction due to a perceived threat, around $63 \%$ of all cases were seen in victims aged 15 y/o and older. Cases where the aggression was intended "predation" were more or less equally distributed between the four age groups (Table 3). As for the nine cases associated 
with a rabid dogs, only five were eligible for codification; two cases were coded as inconclusive and three did not have information about the bite circumstances (N/App).

\section{Children Versus adult}

The bivariate description showed some differences between age groups. Notably, the age distribution included a cluster of very young victims (below $10 \mathrm{y} / \mathrm{o}$ ) in both sexes, and another cluster in the yearly 20s in the males (Figure 3). Accordingly, more males than females were observed in the two older age groups (Table 3). Very young children (0-4 y/o) were potentially exposed only through dogs and through bites (86.6 \%), the exposure site for them was more frequently the head and neck with the highest proportion (23.3\%) and they were less frequently injured during the winter compared to the other age groups. The PEP was more recommended for the oldest age groups (15+y/o) and one-third (34\%) of PEP were administered for victims aged 15 to 34 y/o.

Table 3

Figure 3

MCA was conducted on the 86 cases for which information was available for all variables of interest. The first two dimensions accounted for $39 \%$ and $14 \%$ of the total inertia (amount of variation in the data), respectively and were used for interpretation. Overall, the figure shows a partial association along the first dimension between the following case features: animal not being a dog, positive rabid result, analysis of the animal, exposure trough mucosa, and recommendation for PEP. The second dimension features some differences between cases aged 15-34 y/o and those older. The latter were relatively more associated with disseminated injury or at the lower limbs and with PEP recommendation, whereas cases of 15-34 y/o were relatively more injured at the upper limbs or at the head or neck and following bites and percutaneous exposure, and no recommendation for PEP. No obvious association with age groups was found except for age group 4 (35+y/o) which was associated with the second dimension, determined by exposure site (upper and lower limbs) and exposure type (bite and percutaneous) (Figure $4)$. 
Figure 4

Univariable logistic regression analysis showed that victims aged 0-14 y/o were more frequently females and were more likely to get injured by dogs compared to older victims (Table 4). No other variables were significantly associated with the age groups. No significant association was observed in the multivariable regression analysis of all exposures, whereas the head or neck as exposure site was the only statistically significant results for the dog-related exposures (Table 4).

Table 4. Logistic regression results using children as the reference group 


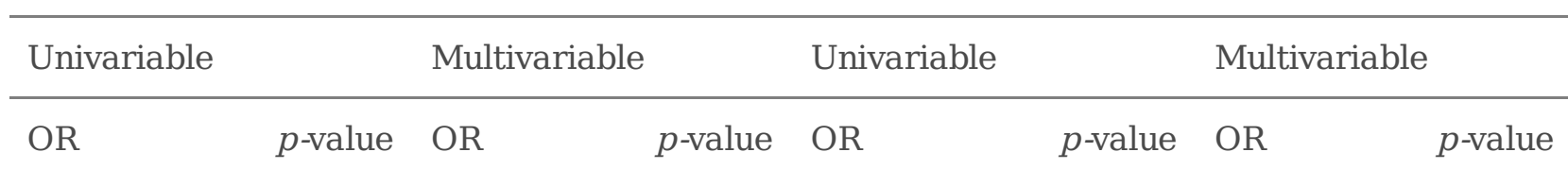

$\begin{array}{llll}(95 \% \mathrm{CI}) & (95 \% \mathrm{CI}) & (95 \% \mathrm{CI}) & (95 \% \mathrm{CI})\end{array}$

\begin{tabular}{|c|c|c|c|c|c|c|c|c|}
\hline \multicolumn{9}{|l|}{ Sex } \\
\hline Males & 1.00 & - & 1.00 & - & 1.00 & - & 1.00 & - \\
\hline \multirow[t]{2}{*}{ Females } & 2.38 & 0.0003 & 1.37 & 0.23 & 2.32 & 0.0006 & 1.54 & 0.19 \\
\hline & $(1.49-3.85)$ & & $(0.74-2.50)$ & & (1.43- 3.85) & & $(0.81-2.94)$ & \\
\hline \multicolumn{9}{|l|}{ Exposure site } \\
\hline Scattered & 1.00 & - & 1.00 & - & 1.00 & - & 1.00 & - \\
\hline \multirow{3}{*}{$\begin{array}{l}\text { Head and } \\
\text { neck }\end{array}$} & 3.30 & 0.07 & 3.38 & 0.06 & 3.67 & 0.05 & 3.75 & 0.05 \\
\hline & (0.94 - & & $(0.95-$ & & $(0.99-14.63)$ & & (1.00- & \\
\hline & 12.42) & & 12.85) & & & & 15.06) & \\
\hline \multirow[t]{2}{*}{ Upper limbs } & 0.96 & 0.94 & 0.97 & 0.95 & 0.90 & 0.86 & 0.85 & 0.79 \\
\hline & $(0.31-3.11)$ & & $(0.31-3.18)$ & & $(0.28-3.01)$ & & $(0.26-2.87)$ & \\
\hline \multirow[t]{2}{*}{ Lower limbs } & 1.14 & 0.82 & 1.16 & 0.80 & 1.05 & 0.93 & 1.05 & 0.93 \\
\hline & $(0.37-3.76)$ & & $(0.37-3.84)$ & & $(0.32-3.55)$ & & $(0.32-3.57)$ & \\
\hline \multirow[t]{3}{*}{ Torso } & 3.00 & 0.41 & 2.59 & 0.48 & 2.67 & 0.46 & 2.36 & 0.52 \\
\hline & $(0.23-$ & & $(0.20-$ & & $(0.21-$ & & $(0.18-$ & \\
\hline & 73.58) & & 64.12) & & 65.79) & & 58.85) & \\
\hline \multicolumn{9}{|l|}{ Animal } \\
\hline Other & 1.00 & - & 1.00 & - & - & - & - & - \\
\hline \multirow[t]{2}{*}{ Dogs } & 3.05 & 0.03 & 2.22 & 0.15 & - & - & - & - \\
\hline & $(1.18-9.42)$ & & $(0.78-7.30)$ & & & & & \\
\hline
\end{tabular}


Ten participants at the local, regional and provincial levels were interviewed: eight were animal or human health professionals and two locals.

The management and reporting of any human case of potential human exposure to rabies in Nunavik can be described as follows (at the time of the interviews). Conditional that a victim injured by an animal seeks medical attention in Nunavik, the case is usually reported to and treated by the local community service centers (CLSC) situated in each of the 14 Nunavik villages. Front line nurses are in charge of the case management and follow-up according to an algorithm. The case is immediately reported to NRPHB as well as the MAPAQ, which provides the expertise on rabies exposure risk if the animal involved is domestic or passes it to the department for expertise on terrestrial fauna of the Québec's Ministry of Forests, Wildlife and Parks (MFFP) if it is a wild animal. At the local level, animal control agents are in charge of the follow-up if the animal is traceable and of the preparation and expedition of the carcass, jointly with the MAPAQ or the MFFP, to the CFIA rabies reference laboratory for testing.

The interviewees identified two major events related to the process of case management. First, around 2014, the CFIA that had been so far involved in rabies surveillance in animals restricted significantly its roles and kept under its responsibility the rabies diagnosis tests only. The other activities (carcass or head preparation and expedition) were consequently transferred to the provincial and regional authorities, which led to more responsibilities for the NRPHB, as well as for the MAPAQ. Second, at the local level, health professionals also noted that a remarkable change had occurred in the process and tools for case management and reporting later on, between 2015 and 2016 with revised Québec's intervention guidelines on rabies and decision tree algorithm. These documents on which front line health professionals rely were modified and put online to facilitate the decision-making process for the management of cases.

Respondents did not mention differences related to months or seasons specific to their roles and responsibilities. However, globally, they told that cases tend to be more frequent during summer. Some linked the dog-related injuries and potential exposure to rabies to some periods where activities such as boating and fishing during which people 
often leave their dogs roaming occur. At the same time, seasonal outbreaks of highly contagious infectious diseases such as parvovirus and distemper was told to affect the dog population dynamic. From an exclusively wild animals perspective, participants pointed out that most cases of exposure involving fauna and almost all rabies cases in wild animals are seen during the cold season (October to March) due to activities such as hunting for furbearing animals or the scarcity of food resources in wild habitats during this season: « [..] you hardly ever see wolves like in town, unless it's like really super cold and super.. there is no food or anything, then they will stay around the dog team area»(L.). These variations were further confirmed by the rabies test results in animals provided by the CFIA: more than $69 \%$ of the rabid animals were tested between December and March over the study period.

Although the roles and activities related to human case management remain globally the same across the province, respondents mentioned some differences at the local level; stakeholders pointed out some issues with the animal control services and positions being very instable and lacking continuity: "I have been here six years, and at least three of them, there has been no By-law enforcement officer" (L.). Moreover, the lack of education and awareness often leads to an uncooperativeness from locals, whether on dog control efforts or PEP and follow-up after an injury. Furthermore, participants said the effectiveness of such control depends to a great extent on the involvement and the engagement of the officers, as a result, villages like Kuujjuaq have had a better control on their dog population over the last years primarily because of the animal control services work: «Our dog situation in the last year and a half, three years has been pretty good [..] they have been pretty good at their job of picking up dogs » (L.).

Participants confirmed that there is no differences regarding their roles and activities in managing exposure cases associated with age. However, healthcare professionals were unanimous on the disproportionate over-representation of children as opposed to adults and the severity of the wounds seen in children under $5 \mathrm{y} / \mathrm{o}$. Most respondents related these differences to the inadequate behavior of children and adolescents with dogs in Nunavik: «I have seen situations there, walking in the villages where children were playing, or were 
aggressive [towards dogs] » (M.). As for adults, participants mentioned that some activities including hunting and mushing as risk factors especially for males.

\section{Discussion}

This study aimed at describing the cases of potential human exposure to rabies in Nunavik, at determining differences between children and adults, and at interpreting the findings considering the relevant context. It estimated at 2.5 cases per 1,000 population the average annual incidence of potential human exposure to rabies in Nunavik, identified 15 exposures with true rabid animals, and highlighted the importance of dogs for potential and true exposure of humans to rabies ( $92 \%$ of exposures related to dog bites and nine dogs out of the 15 positive animals). Those actual exposures and the incidence of potential exposure to rabies in Nunavik almost 10 times higher than what has been reported in Canada ( 7 , 19) confirm that rabies and potential exposure to it is an important issue of high public health concern in this region. It is worth to note that no actual human rabies have occurred in Nunavik thanks to the strict case management of all potential rabies exposure cases that presented themselves to the medical authorities. More precisely, the study revealed that all potential cases have been managed adequately regardless of their age and gender, of the moment of the exposure and in all Nunavik villages.

These figures from the 14 Inuit remote villages in Nunavik confirm the higher risk of dog bites and of potential exposures to rabies reported in other remote and indigenous communities in North America (37); $(13,15,38,39)$. This higher risk has been linked to the socio-economic status and to other determinants such as structural, social or cultural disparities, including limited access to animal health services, to animal training capacities, insufficient law enforcement and education on responsible pet ownership (15, $40,41)$. In addition, numerous stray or free-roaming dogs were pointed out for high dog bite incidence in indigenous remote societies $(26,38,42)$. All the above-mentioned determinants of more frequent dog bites and potential exposure to rabies may well be applicable to Nunavik villages according to our knowledge and understanding gained from several research projects tackling the human health issues at the human-dog interface in northern Québec $(26,43,44)$. This suggests that reducing potential exposure to rabies through dog bite requires several measures on specific modifiable determinants, such as law enforcement, education (of children, parents, dog owners, etc.), animal dog health services, whereas the other determinants may change only slowly, notably the socio-economics and cultural ones.

Our study highlighted two major profiles of victims mainly based on their age, sex and the animal involved. The first profile is made of children aged up to $14 \mathrm{y} / \mathrm{o}$, males or females, mostly exposed through dogs during play. They were also more likely to sustain injuries in the head and neck. This seems universal to children and certainly related to their physical features and their maturity under development $(30,45,46)$.

The second profile is made of young adult males (aged 15 to $34 \mathrm{y} / \mathrm{o}$ ) exposed through wildlife or dogs (following a reaction type of aggression) and with injuries at the upper limbs. In addition, the exposure during outdoor activities such as hunting or mushing occurred mainly among this profile. Men in northern 
communities traditionally practice such activities during fall or winter. The association between age and gender has been mentioned in other studies $(16,47,48)$, however the patterns seem to be different depending on the social environment and the related risk factors as illustrated by the current study. This finding sustains the need to tailor a specific prevention program to this unique profile.

Investigation of exposure circumstances in cases involving dogs confirmed that most injuries (56\%) were the result of an intentional or unintentional form of "provocation". Although the use of the term provoked is very controversial, it has been acknowledged that some forms of interactions are highly prone to target motives of aggressive behavior in dogs such as territoriality, protection and guard or fear and threat $(5$, $32,46,49)$. Although sometimes labeled as "play-bites" or positive interactions (50), it is important to distinguish situations where the human and the dog were playing, from those where the intention to play comes only from the victim's side (33). Misinterpretation of signaling behavior of the dog and inappropriate attitude in risky situations (female with litter, a sleeping dog) are often overlooked although they play a major role in triggering the aggressive behavior, especially with children (50-52). Future prevention programs should focus on aspects such as teaching body language and appropriate/safe interactions, especially for the children.

Over the study period, reported cases of potential exposure to rabies in Nunavik increased significantly from 2013 to 2017, the end of the study period. Our exploration of the context that included a specific question about trend over time failed to provide a clear explanation for this rise. We have evidences that rabies in wildlife was rather stable over the study period, and no evidences that the dog populations had increased, hence the hypotheses of more frequent contacts between human beings and dogs or with rabid animals cannot be supported. Two significant changes over time were reported: in the responsibilities of the operation of rabies surveillance in animals in 2014-2015 and in the process and tools for the management and reporting (from front line medical staff to Public Health staff) of potential human exposure to rabies. It is difficult to see a link between the former and the increased number of potential exposures to rabies. The latter changes might have changed upward the reporting; however, considering that rabies had been a public health issue for a long time in the region, it is difficult to believe that the front line was not already diligent in the management and reporting of potential exposure prior to the changes. A more probable explanation might be that the changes within the medical and public health system indirectly raised awareness about rabies and the importance of medical consultation in case of exposure among the general public, leading to an increase in the number of people consulting the medical services for potential exposure to rabies.

No clear pattern of seasonality was found, however our results showed that more cases of injuries were declared during the months of May and August, similar findings have been previously reported $(47,53)$. One hypothesis is that contacts with dogs increase during the long photoperiod season, especially since dogs are usually kept outside in Nunavik (43). In addition, the context analysis revealed that during seasonal activities such as boating and fishing, locals tend to stay away from their homes for days, leaving their dogs roaming unleashed. 
Although cases of rabid animals were rare and more or less stable over the ten-year-period, potential exposures appeared higher in villages of the Hudson Bay compared to the Ungava Bay. Information related to rabies dynamic in wildlife as well as the epidemiological factors contributing in the contact rate between wild and domestic animals is necessary to in order to identify the hot spots and design prevention programs accordingly $(4,54)$. Mass vaccination of dogs can be a barrier for human exposure; however, since the immunization status of dogs is not well documented in Nunavik, it is difficult to estimate the coverage rates and their impact.

One strength of this study was the use of data systematically collected and compiled on potential human exposure to rabies that included data from the human and the animal sides over a long and recent period. The second strength is the thorough uni- and multivariable description of all data available prior to formal test for the difference between ages. The last major strength was the context analysis undertaken to help interpreting the findings. As a retrospective study, some biases were inherent to the collection and analysis of data; using registries of only declared cases, we might overlook a fraction of actual potential exposures, with possibly different characteristics $(8,55)$. Considering that no human rabies cases occurred in the region for several decades, we can be relatively sure that the genuine exposure to rabies were well captured, meaning that our figures on incidence may underestimate the risk for potential exposure but not for exposure to rabid animals. Missing data for some variables tended to limit the validity of their estimate and their use for statistical analysis; nevertheless, missing data were rare for the most important variables, especially the one involved in defining the two victim's profiles. Obviously, the study targeted Nunavik and its findings cannot be generalized to other parts of the Arctic without caution.

\section{Conclusion}

The study quantified the high risk of potential exposure to rabies and the relative importance of dog bites concerning this risk in the northern Inuit villages in Quebec. Although rabies is a true issue of public health concern in Nunavik, the medical services and their partners have been diligent in managing all cases of potential of rabies and following-up or testing the implied animal, respectively, with no actual cases of human rabies.

The study also identified and characterized two peculiar risk profiles based on age and gender for potential exposure to rabies in Nunavik: the children (female or male) bitten by a dog while playing with it, and the young male adults in contact with wildlife during outdoor activities. Both profiles deserved targeted prevention programs to reduce the burden of potential rabies exposures.

Our findings showed an increase of reported cases of potential exposure to rabies. No final explanation was found; raising awareness in the general public about rabies as an indirect effect of process change in management and reporting within the health sector was the most probable hypothesis. The increasing incidence should be confirmed for the years after 2017 and explained considering its possible impacts on human life (possible increase of true exposure to rabies) and on the health system (more cases to manage and to report, more PEPs and follow-ups). 


\section{Abbreviations}

CFIA: Canadian Food Inspection Agency

CHIRPP: Canadian Hospitals Injury Reporting and Prevention Program

CLSC: Local Community Services Centers

MAPAQ: Ministry of Agriculture, Fisheries and Food of Quebec

MCA: Multiple correspondence analysis

MFFP: Ministry of Forests, Wildlife and Parks of Quebec

NRPHB: Nunavik Regional Public Health Board

PEP: Post-Exposure Prophylaxis

SES: Socio-economic status

US: United States

\section{Declarations}

\section{Ethical approval and consent to participate}

All procedures performed in the present study involving human participants were in accordance with the standards of the ethical committees at the University of Montreal (certificate number: 18-122-CERES-D) and with the 1964 Helsinki Declaration and its later amendments or comparable ethical standards.

\section{Consent for publication}

Not applicable.

\section{Availability of data and materials}

The data that support the findings of this study are available from Public Health Department of Nunavik but restrictions apply to the availability of these data, which were used under license for the current study, and so are not publicly available. Data are however available from the authors upon reasonable request and with permission of the Public Health Department of Nunavik.

\section{Competing interests}


The authors declare no conflict of interest.

\section{Funding}

The funding for this study was provided by the Ministry of Higher Education and Scientific Research of Tunisia as well as the Canadian Institutes of Health Research.

\section{Authors contributions}

Sarah Mediouni: Primary data collection, analysis and interpretation of data, manuscript writing

Mario Brisson: Access to data, reviewing of preliminary results, adjustment of the study design, manuscript revision and approval

André Ravel: Conceptualization of the study design and research proposal, statistical analysis, supervision during all the steps of the research study, manuscript revision and approval

\section{Acknowledgements}

Authors would like to thank all interviewees, the Nunavik Regional Public Health Board for the availability of the data, the Ministry of Agriculture, Fisheries and Food of Quebec for providing an internal report on animal-related injuries, and the Canadian Food Inspection Agency for providing relevant data on positive rabid animals.

\section{References}

1.American Veterinary Medical Association. A community approach to dog bite prevention. Journal of the American Veterinary Medical Association. 2001;218(11):1732-49.

2.Parrish HM, Clack FB, Brobst D, Mock JF. Epidemiology of dog bites. Public Health Reports (18961970). 1959:891-903.

3.Adomako B-Y, Baiden F, Sackey S, Ameme DK, Wurapa F, Nyarko KM, et al. Dog Bites and Rabies in the Eastern Region of Ghana in 2013-2015: A Call for a One-Health Approach. Journal of tropical medicine. 2018;2018:6139013.

4.Aenishaenslin C, Simon A, Forde T, Ravel A, Proulx JF, Fehlner-Gardiner C, et al. Characterizing rabies epidemiology in remote Inuit communities in Quebec, Canada: a "One Health" approach. Ecohealth. 2014;11(3):343-55. 
5.Ministère de la santé et des services sociaux du Québec. Guide d'intervention visant la prévention de la rage humaine. 2016.

6.World Health Organization. Human rabies: 2016 updates and call for data. 2017.

7.Clarke NM, Fraser D. Animal control measures and their relationship to the reported incidence of dog bites in urban Canadian municipalities. The Canadian veterinary journal = La revue veterinaire canadienne. 2013;54(2):145-9.

8.Guy NC, Luescher UA, Dohoo SE, Spangler E, Miller JB, Dohoo IR, et al. A case series of biting dogs: characteristics of the dogs, their behaviour, and their victims. Applied Animal Behaviour Science. 2001;74(1):43-57.

9.Kahn A, Robert E, Piette D, De Keuster T, Lamoureux J, Leveque A. Prevalence of dog bites in children: a telephone survey. European journal of pediatrics. 2004;163(7):424.

10.Sacks JJ, Kresnow M-j, Houston B. Dog bites: how big a problem? Injury prevention. 1996;2(1):52-4.

11.Gilchrist J, Sacks J, White D, Kresnow M. Dog bites: still a problem? Injury prevention. 2008;14(5):296301.

12.Loder RT. The demographics of dog bites in the United States. Heliyon. 2019;5(3):e01360.

13.Castrodale L. Hospitalizations resulting from dog bite injuries-Alaska, 1991-2002. International journal of circumpolar health. 2007;66(4):320-7.

14.Ponsich A, Goutard F, Sorn S, Tarantola A. A prospective study on the incidence of dog bites and management in a rural Cambodian, rabies-endemic setting. Acta tropica. 2016;160:62-7.

15.Raghavan M. Exploring the relationship between socioeconomic status and dog-bite injuries through spatial analysis. Rural and remote health. 2014;14(3):2846.

16.Alberghina D, Virga A, Buffa SP, Panzera M. Incidence and characteristics of hospitalizations after dog's bite injuries in Sicily (Italy) between 2012-2015. Veterinaria italiana. 2017;53(4):315-20.

17.Schwebel DC, McClure LA, Severson J. Evaluating a website to teach children safety with dogs. Injury prevention. 2015;21(1):e2.

18.Shen J, Rouse J, Godbole M, Wells HL, Boppana S, Schwebel DC. Systematic Review: Interventions to Educate Children About Dog Safety and Prevent Pediatric Dog-Bite Injuries: A Meta-Analytic Review. Journal of pediatric psychology. 2017;42(7):779-91.

19.Public Health Agency Canada. CHIRPP INJURY BRIEF. Injuries associated with Non-Fatal Dog Bites 1990-2003, All ages. 2005. 
20.Lang ME, Klassen T. Dog bites in Canadian children: a five-year review of severity and emergency department management. Canadian journal of emergency medicine 2015;7(05):309-14.

21.Nunavik Regional Board of Health and Social Services. Health Profile of Nunavik 2011: Demographic and Socioeconomic Conditions. 2011.

22.http://www.nunavik-tourism.com/accueil.aspx Accessed on 16/04/2019

23.Laugrand F. Hunters, predators and prey: Inuit perceptions of animals. Oosten JG, MyiLibrary L, editors: New York: Berghahn Books; 2015.

24.Laugrand F. Introduction: cultures inuit, gouvernance et cosmopolitiques/Introduction: Inuit cultures, governance and cosmopolitics. Études/Inuit/Studies. 2014;38(1/2):7-21.

25.Lévesque F. Là où le bât blesse. Soixante ans de gestion des chiens au Nunavik. Bêtes à pensées: Visions des mondes animaux2015. p. 65.

26.Simon A, Saint-Charles J, Ravel A. Succès mitigé du contrôle des chiens au Nunavik: comprendre les facteurs en cause pour s'orienter vers des solutions. Banque PolEthicas 2017.

27.Tabel $\mathrm{H}$, Corner AH, Webster WA, Casey CA. History and epizootiology of rabies in Canada. The Canadian veterinary journal = La revue veterinaire canadienne. 1974;15(10):271-81.

28.Rabies in Canada http://www.inspection.gc.ca/animals/terrestrial-

animals/diseases/reportable/rabies/rabies-in-canada/eng/1356156989919/1356157139999 Accessed on 03 Feb 2019

29.Mills DS, Westgarth C. Dog bites: a multidisciplinary perspective: Sheffield, UK: 5M Publishing; 2017.

30.0xley JA, Christley R, Westgarth C. Contexts and consequences of dog bite incidents. Journal of Veterinary Behavior. 2018;23:33-9.

31.Borchelt PL. Aggressive behavior of dogs kept as companion animals: Classification and influence of sex, reproductive status and breed. Applied Animal Ethology. 1983;10(1):45-61.

32.Understanding Dog Aggression https://www.calgaryhumane.ca/wpcontent/uploads/2014/07/Understanding_Dog_Aggression.pdf Accessed on 22/12/2018

33.Messam LLM, Kass PH, Chomel BB, Hart LA. Risk factors for dog bites occurring during and outside of play: are they different? Preventive veterinary medicine. 2012;107(1-2):110-20.

34.Shewell PC, Nancarrow JD. Dogs that bite. British Medical Journal. 1991;303(6816):1512.

35.Ancelle T. Statistique, épidémiologie. 4e édition.. ed: Paris: Éditions Maloine; 2017. 
36.Gordis L. Epidemiology. Fifth edition.. ed: Philadelphia, PA: Elsevier/Saunders; 2014.

37.Schurer J, Phipps K, Okemow C, Beatch H, Jenkins E. Stabilizing dog populations and improving animal and public health through a participatory approach in indigenous communities. Zoonoses and public health. 2015;62(6):445-55.

38.Bjork A, Holman RC, Callinan LS, Hennessy TW, Cheek JE, McQuiston JH. Dog bite injuries among American Indian and Alaska Native children. The Journal of pediatrics. 2013;162(6):1270-5.

39.Raghavan M. Fatal dog attacks in Canada, 1990-2007. The Canadian veterinary journal = La revue veterinaire canadienne. 2008;49(6):577-81.

40.Ndon JA, Jach GJ, Wehrenberg WB. Incidence of dog bites in Milwaukee, Wis. Wisconsin medical journal. 1996;95:237-41.

41.Shuler CM, DeBess EE, Lapidus JA, Hedberg K. Canine and human factors related to dog bite injuries. Journal of the American Veterinary Medical Association. 2008;232(4):542-6.

42.Vargo D, DePasquale JM, Vargo AM. Incidence of dog bite injuries in American Samoa and their impact on society. Hawai'i journal of medicine \& public health: a journal of Asia Pacific Medicine \& Public Health. 2012;71(1):6-12.

43.Aenishaenslin C, Brunet P, Lévesque F, Gouin GG, Simon A, Saint-Charles J, et al. Understanding the Connections Between Dogs, Health and Inuit Through a Mixed-Methods Study. EcoHealth. 2018:1-10.

44.Simon A, Saint-Charles J, Lévesque F, Ravel A. Problématiques des chiens à Kuujjuaq: comment une approche de recherche en écosanté peut-elle aider à les résoudre? Études/Inuit/Studies. 2018.

45.Kimble RM, Dallow N, Franklin R, Wallis B. Dog bites in Australian children. The Medical Journal of Australia. 2011;195(11):635-6.

46.Ozanne-Smith J, Ashby K, Stathakis V. Dog bite and injury prevention-analysis, critical review, and research agenda. Injury prevention. 2001;7(4):321-6.

47.Park JW, Kim DK, Jung JY, Lee SU, Chang I, Kwak YH, et al. Dog-bite injuries in Korea and risk factors for significant dog-bite injuries: A 6-year cross-sectional study. PloS one. 2019;14(2):e0210541-e.

48.Quirk JT. Non-fatal dog bite injuries in the USA, 2005-2009. Public Health. 2012;126(4):300-2.

49.Rabies. What type of exposure occurred? https://www.cdc.gov/rabies/exposure/type.html Accessed on $26 / 02 / 2019$

50.Reisner IR, Nance ML, Zeller JS, Houseknecht EM, Kassam-Adams N, Wiebe DJ. Behavioural characteristics associated with dog bites to children presenting to an urban trauma centre. Injury prevention. 2011;17(5):348-53. 
51.Davis AL, Schwebel DC, Morrongiello BA, Stewart J, Bell M. Dog bite risk: an assessment of child temperament and child-dog interactions. Int J Environ Res Public Health. 2012;9(8):3002-13.

52.Overall KL, Love M. Dog bites to humans-demography, epidemiology, injury, and risk. Journal of the American Veterinary Medical Association. 2001;218(12):1923-34.

53.Fasil M, Kedir H, Garoma G, Dessalegn S, Abraham A, Assefa D. Total case of dog bites to humans and seasonal patterns of the bites. Ethiopian Veterinary Journal. 2011;15(2):103-8.

54.Mork T, Prestrud P. Arctic rabies -a review. Acta veterinaria Scandinavica. 2004;45(1-2):1-9.

55.de Keuster T, Butcher R. Preventing dog bites: risk factors in different cultural settings. Veterinary journal (London, England: 1997). 2008;177(2):155-6.

\section{Table}

Table 3. Characteristics of potential human exposures to rabies by age group and percentage of the total in each group, Nunavik 2008-2017 


\begin{tabular}{lrrrrrrrrrrr}
\hline \multicolumn{2}{c}{ Total } & & {$[0-4]$} & & {$[5-14]$} & & {$[15-34]$} & & {$[35+]$} & & NA \\
\hline $\mathrm{n}$ & $\%$ & $\mathrm{n}$ & $\%$ & $\mathrm{n}$ & $\%$ & $\mathrm{n}$ & $\%$ & $\mathrm{n}$ & $\%$ & $\mathrm{n}$ & $\%$ \\
\hline
\end{tabular}

\begin{tabular}{|c|c|c|c|c|c|c|c|c|c|c|c|c|}
\hline Sex & & & & & & & & & & & & \\
\hline Male & 198 & 61.9 & 16 & 53.3 & 56 & 50.9 & 84 & 73.7 & 41 & 67.2 & 2 & 20.0 \\
\hline Female & 120 & 37.5 & 14 & 46.7 & 54 & 49.1 & 30 & 26.3 & 20 & 32.8 & 1 & 40.0 \\
\hline NA & 2 & 0.6 & 0 & 0 & 0 & 0 & 0 & 0 & 0 & 0 & 2 & 40.0 \\
\hline \multicolumn{13}{|l|}{ Exposure type } \\
\hline Bite & 244 & 76.2 & 26 & 86.6 & 81 & 73.6 & 87 & 76.3 & 46 & 75.4 & 4 & 80.0 \\
\hline Percutaneous & 8 & 2.5 & 0 & 0 & 5 & 4.5 & 2 & 1.8 & 1 & 1.6 & 0 & 0 \\
\hline Mucous & 16 & 5 & 2 & 6.7 & 4 & 3.6 & 8 & 7.0 & 2 & 3.3 & 0 & 0 \\
\hline NA & 52 & 16.2 & 2 & 6.7 & 20 & 18.2 & 17 & 14.9 & 12 & 19.7 & 1 & 20.0 \\
\hline
\end{tabular}

\section{Exposure site}

\begin{tabular}{lcccccccccccc}
\hline Disseminated & 15 & 4.7 & 2 & 6.7 & 4 & 3.6 & 3 & 2.6 & 6 & 9.8 & 0 & 0 \\
\hline Lower limbs & 67 & 20.9 & 5 & 16.7 & 24 & 21.8 & 22 & 19.3 & 16 & 26.2 & 0 & 0 \\
\hline Upper limbs & 77 & 24.1 & 6 & 20.0 & 24 & 21.8 & 36 & 31.6 & 11 & 18.0 & 0 & 0 \\
\hline Head and neck & 32 & 10 & 7 & 23.3 & 15 & 13.6 & 8 & 7.0 & 2 & 3.3 & 0 & 0 \\
\hline Trunk & 3 & 0.9 & 1 & 3.3 & 1 & 0.9 & 0 & 0.0 & 1 & 1.6 & 0 & 0 \\
\hline NA & 126 & 39.4 & 9 & 30.0 & 42 & 38.2 & 45 & 39.5 & 25 & 41.0 & 5 & 100 \\
\hline Animal type & & & & & & & & & & & \\
\hline Dog & 293 & 91.6 & 30 & 100 & 102 & 92.7 & 101 & 88.6 & 55 & 90.2 & 5 & 100 \\
\hline Other & 23 & 7.2 & 0 & 0 & 5 & 4.5 & 12 & 10.5 & 6 & 9.8 & 0 & 0 \\
\hline NA & 4 & 1.2 & 0 & 0 & 3 & 2.7 & 1 & 0.9 & 0 & 0 & 0 & 0 \\
\hline PEP & & & & & & & & & & & \\
\hline Recommended & 99 & 30.9 & 7 & 23.3 & 27 & 24.5 & 34 & 29.8 & 28 & 45.9 & 3 & 60.0 \\
\hline Not recommended & 133 & 41.6 & 16 & 53.3 & 41 & 37.3 & 56 & 49.1 & 20 & 32.8 & 0 & 0 \\
\hline NA & 27.5 & 7 & 23.3 & 42 & 38.2 & 24 & 21.1 & 13 & 21.3 & 2 & 40.0 \\
\hline
\end{tabular}

Exposure season

Winter

$\begin{array}{llllllllllll}65 & 20.3 & 3 & 10.0 & 25 & 22.7 & 24 & 21.1 & 11 & 18.0 & 2 & 40.0\end{array}$ 


\begin{tabular}{lcccccccccccc} 
Spring & 80 & 25 & 9 & 30.0 & 25 & 22.7 & 30 & 26.3 & 16 & 26.2 & 0 & 0 \\
\hline Summer & 93 & 29.1 & 11 & 36.7 & 33 & 30.0 & 34 & 29.8 & 14 & 23.0 & 1 & 20.0 \\
\hline Autumn & 81 & 25.3 & 6 & 20.0 & 27 & 24.5 & 26 & 22.8 & 20 & 32.8 & 2 & 40.0 \\
\hline NA & 1 & 0.3 & 1 & 3.3 & 0 & 0 & 0 & 0 & 0 & 0 & 0 & 0 \\
\hline
\end{tabular}

\section{Exposure day}

\begin{tabular}{lcccccccccccc}
\hline Weekday & 237 & 74.1 & 19 & 63.3 & 85 & 77.3 & 87 & 76.3 & 42 & 68.9 & 4 & 80.0 \\
\hline Weekend & 83 & 25.9 & 11 & 36.7 & 25 & 22.7 & 27 & 23.7 & 19 & 31.1 & 1 & 20.0 \\
\hline NA & 0 & 0 & 0 & 0 & 0 & 0 & 0 & 0 & 0 & 0 & 0 & 0 \\
\hline
\end{tabular}

Animal test result

\begin{tabular}{lcccccccccccc}
\hline Positive & 15 & 4.7 & 1 & 3.3 & 2 & 1.8 & 10 & 8.8 & 2 & 3.3 & 0 & 0 \\
\hline Negative & 210 & 65.6 & 19 & 63.3 & 72 & 65.5 & 74 & 64.9 & 41 & 67.2 & 4 & 80 \\
\hline NA & 89 & 27.8 & 10 & 33.3 & 33 & 30.0 & 28 & 24.6 & 17 & 27.9 & 1 & 20 \\
\hline N/App & 6 & 1.9 & 0 & 0 & 3 & 2.7 & 2 & 1.8 & 1 & 1.6 & 0 & 0 \\
\hline
\end{tabular}

Exposure circumstances ${ }^{[1]}$

\begin{tabular}{lcccccccccccc}
\hline Play/ communication & 26 & 17.1 & 7 & 43.8 & 12 & 21.8 & 5 & 10.2 & 1 & 3.6 & 1 & 25.0 \\
\hline Reaction & 59 & 38.8 & 5 & 31.2 & 16 & 29.1 & 25 & 51.0 & 12 & 42.9 & 1 & 25.0 \\
\hline Aggression/ predation & 10 & 6.6 & 2 & 12.5 & 3 & 5.5 & 1 & 2.0 & 4 & 14.3 & 0 & 0 \\
\hline Inconclusive & 51 & 33.6 & 1 & 6.2 & 24 & 43.6 & 16 & 32.7 & 10 & 35.7 & 0 & 0 \\
\hline N/App & 6 & 3.9 & 1 & 6.2 & 0 & 0 & 2 & 4.1 & 1 & 3.6 & 2 & 50.0 \\
\hline
\end{tabular}

[1] Cases including dogs only ( $N=152)$

Figures 

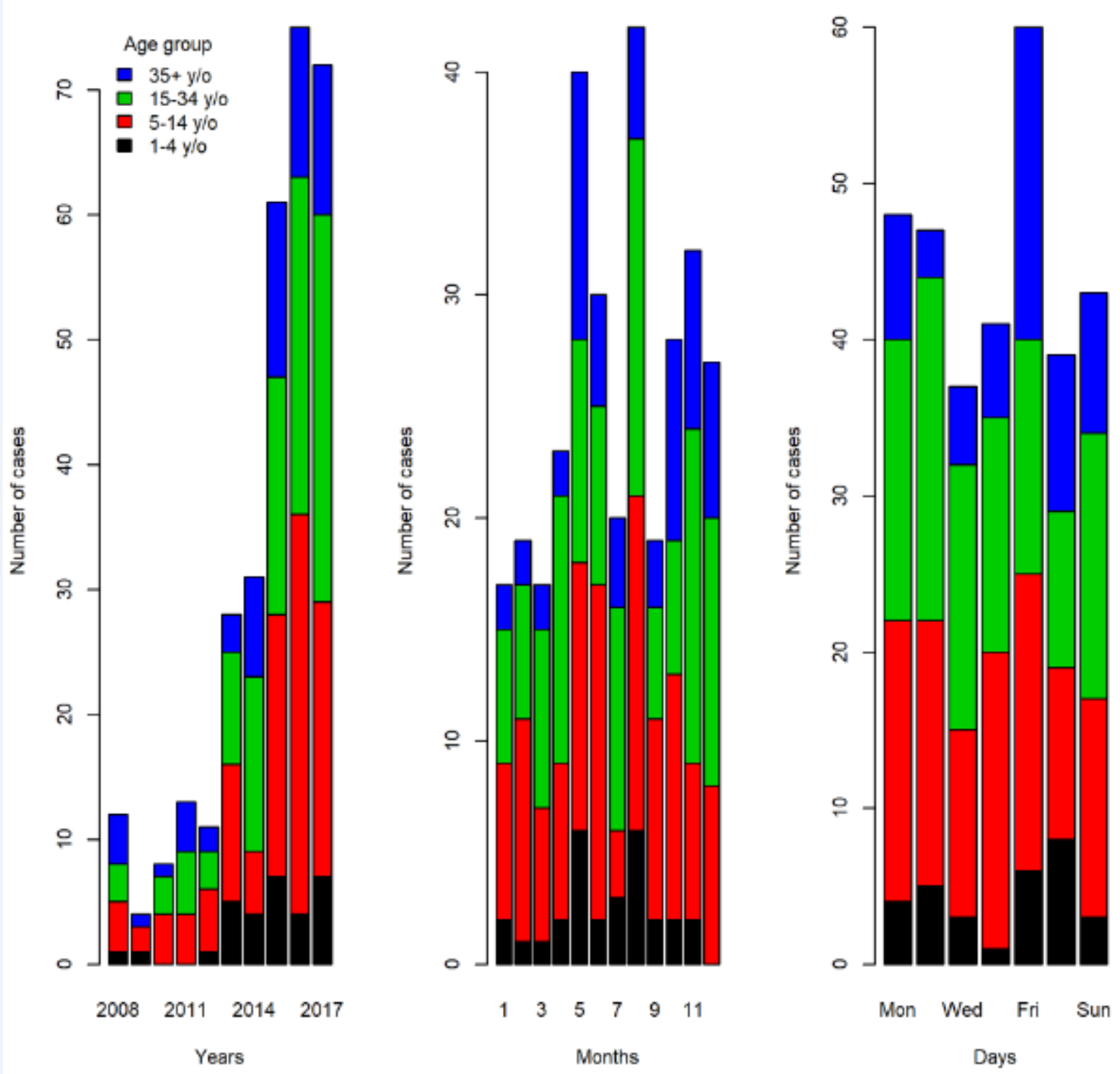

Figure 1

Distribution of cases of potential human exposures to rabies by years, months, and days of the week by age group, Nunavik 2008-2017 


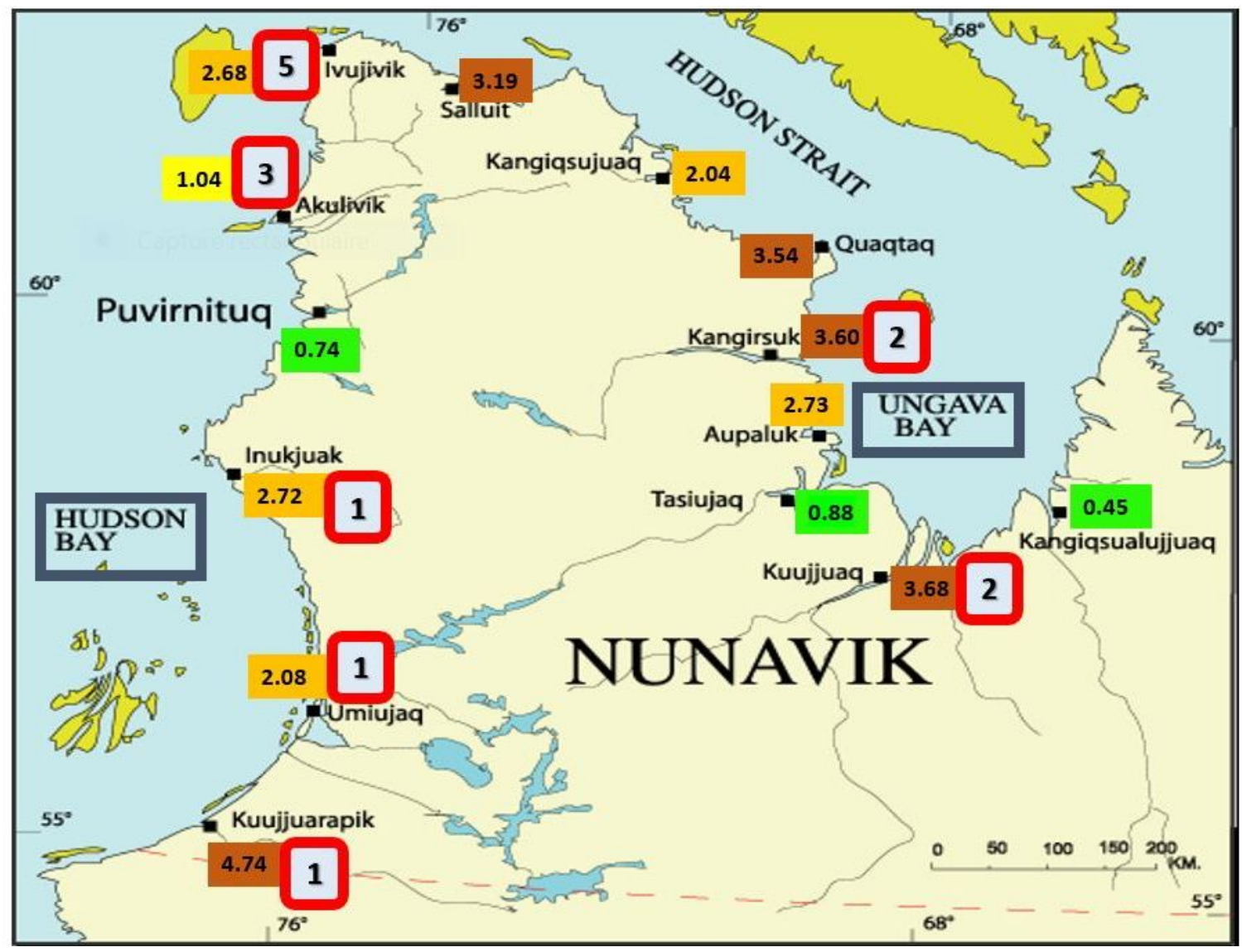

Figure 2

Adjusted annual cumulative incidence (/1,000 population) of potential human exposures to rabies and number of positive rabid animal per village, Nunavik 2008-2017 


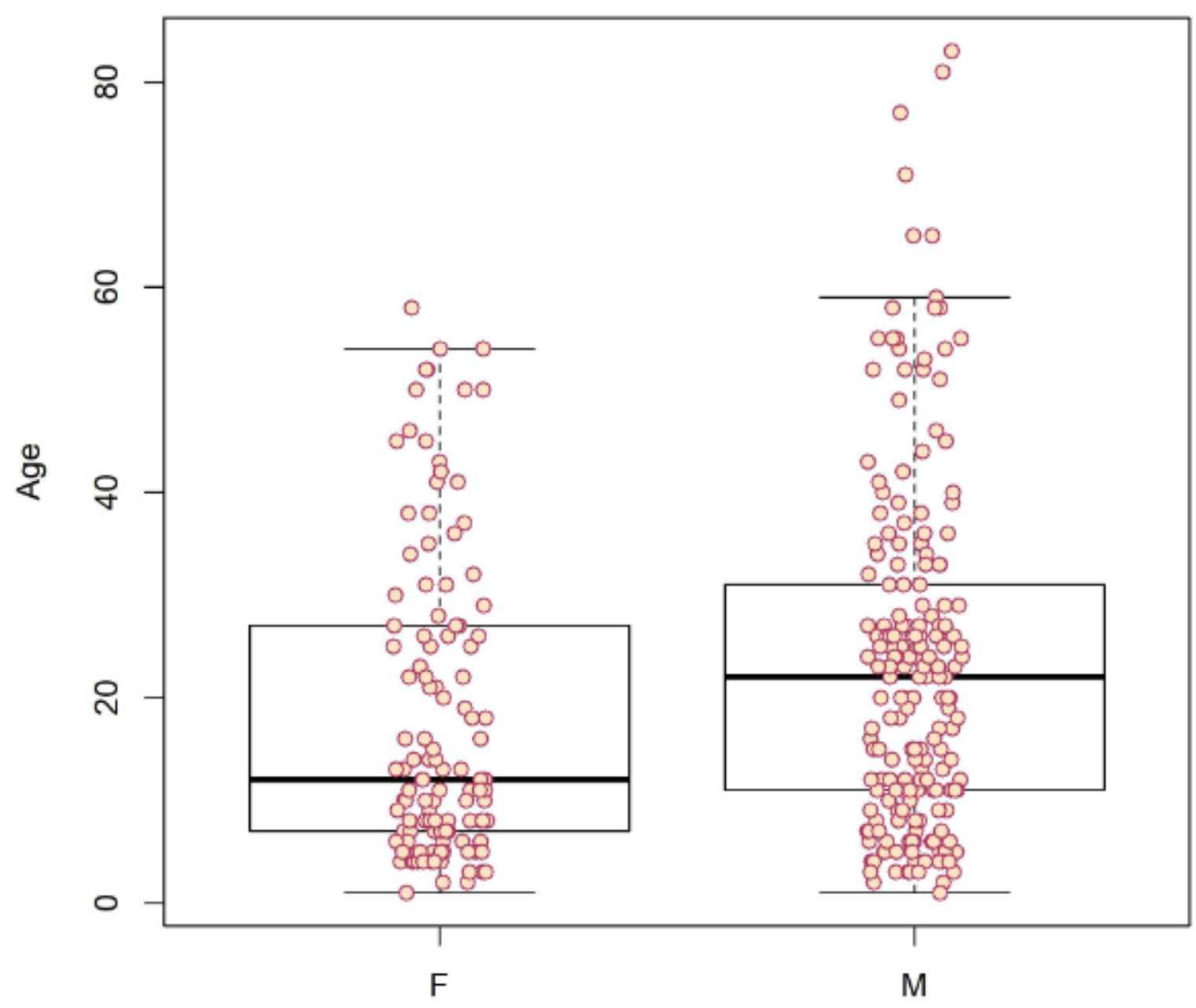

Sex

Figure 3

Age distribution of potential human exposures to rabies by sex, Nunavik 2008-2017 


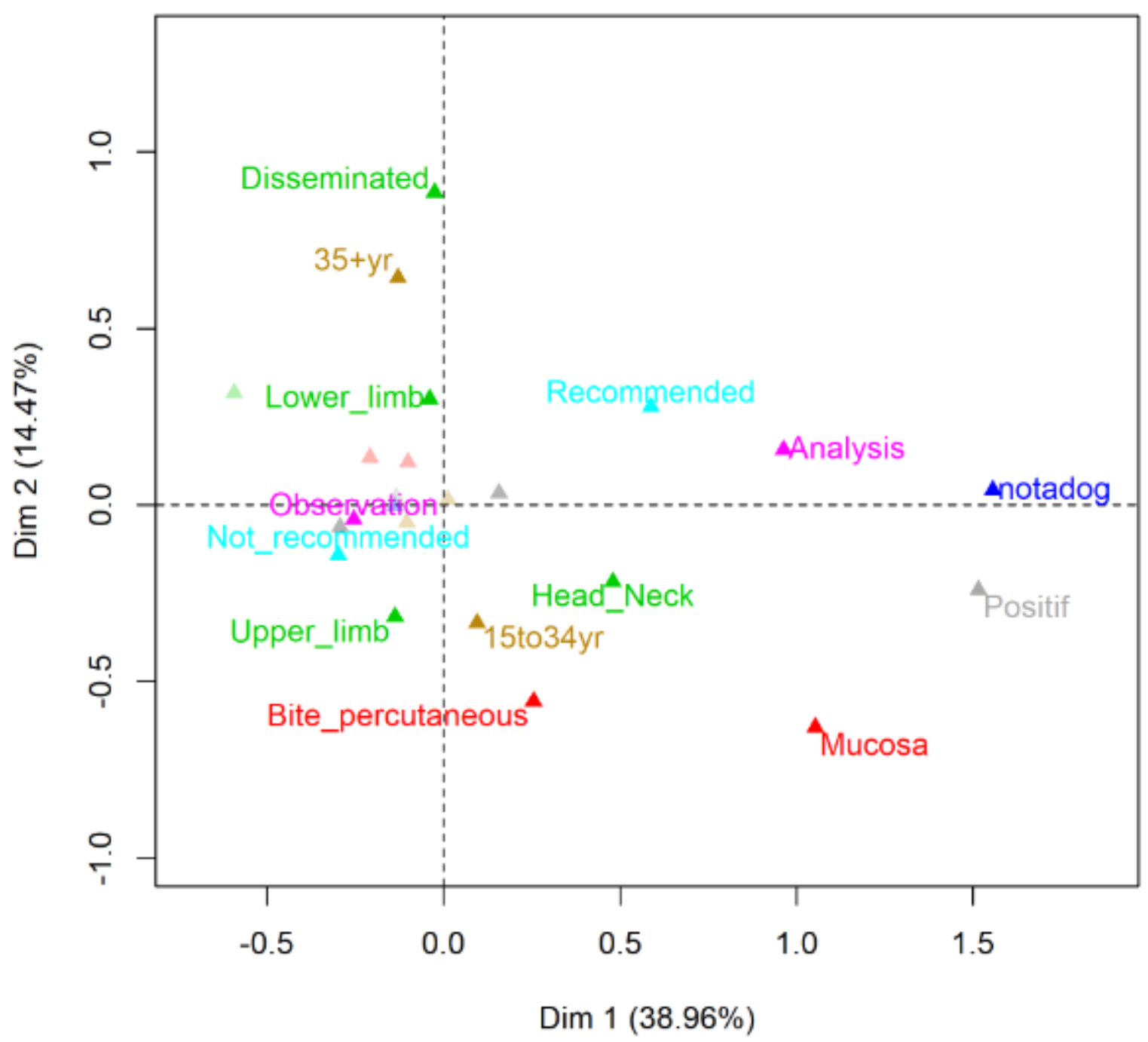

\section{Figure 4}

MCA plot (or projection) on the first two dimensions of age group (0-4, 5-14, 15-34, 35+ y/o; in orange), sex $(M, F)$ and the following variables describing the exposure: the exposure site (lower limbs, upper limbs, head or neck, disseminated, trunk; in green), the exposure type (bite, mucosa, percutaneous, bite and percutaneous; in red), the animal involved (dog , not a dog; in blue), the PEP recommendation decision (recommended, not recommended; in light blue), the animal follow-up (observation, analysis; in pink) and the animal test result for rabies (negative, positive; in light gray). 